\title{
ENSINO DE PORTUGUÊS COMO LÍNGUA MATERNA: REFLEXÕES E ATIVIDADES
}

\section{TEACHING PORTUGUESE AS A MOTHER LANGUAGE: REFLECTIONS AND ACTIVITIES}

\author{
Paula Fernanda Eick Cardoso ${ }^{1}$ \\ Camila Martins Vellar ${ }^{2}$
}

\begin{abstract}
RESUMO: Nas aulas de Língua Portuguesa, ainda é comum a ênfase em nomenclaturas e classificações, baseadas na Gramática Tradicional. No entanto, ao trabalhar atividades de leitura, interpretação e produção textual, percebemos que o conhecimento gramatical por si só não é suficiente para o desenvolvimento da competência comunicativa nos alunos. Desse modo, no presente artigo, apresentaremos a nossa compreensão sohbre o ensino de língua materna, tomando por base estudos realizados por importantes linguistas brasileiros. Posteriormente, apresentaremos uma proposta de atividades que foi aplicada a alunos do ensino médio, seguida de uma breve análise sobre os elementos presentes nela. A atividade baseia-se na crônica do Luís Fernando Veríssimo intitulada "Exigências da Vida Moderna" e foi proposta para a modalidade presencial, anteriormente à pandemia. Ao final da aplicação, constatamos uma boa recepção da turma em relação à atividade realizada, visto que a participação dos alunos foi bastante significativa. Tomamos por base autores como Sírio Possenti, Irandé Antunes, Ferrarezzi Júnior e Carvalho e Juanito Avelar, os quais são importantes referências no que se refere à questão do ensino de Língua Portuguesa no Brasil.
\end{abstract}

PALAVRAS-CHAVE: Ensino. Língua Portuguesa. Atividades.

\begin{abstract}
In Portuguese language classes, the emphasis on nomenclatures and classifications, based on Traditional Grammar, is still common. However, when working with reading, interpreting and textual production activities, we realize that grammatical knowledge alone is not sufficient for the development of communicative competence in students. Thus, in this article, we will present our understanding of mother tongue teaching, based on studies carried out by important Brazilian linguists. Subsequently, we will present a proposal for activities that was applied to high school students, followed by a brief analysis of the elements present in it. The activity is based on Luís Fernando Veríssimo chronicle entitled "Demands of Modern Life" and was proposed for the face-to-face modality, prior to the pandemic. At the end of the application, we found a good reception from the class in relation to the activity carried out, since the participation of students was quite significant. We take as a basis authors such as Sírio Possenti, Irandé Antunes,
\end{abstract}

${ }^{1}$ Professora do Centro de Letras e Comunicação da Universidade Federal de Pelotas. Possui Doutorado em Linguística e Letras pela Pontifícia Universidade Católica do Rio Grande do Sul. E-mail: paulaeick@terra.com.br

${ }^{2}$ Mestranda em Educação pela Universidade Federal de Pelotas, PPGE/UFPEL. E-mail: camilamartinsvellar@gmail.com 
PERcursos Linguísticos • Vitória (ES) •v. $11 ・$ •n. 28 • 2021 • ISSN: 2236-2592

Ferrarezzi and Carvalho and Juanito Avelar, who are important references with regard to the issue of Portuguese language teaching in Brazil.

KEYWORDS: Teaching. Portuguese language. Activities.

\section{Introdução}

As atividades das aulas de língua portuguesa deveriam ser preparadas em torno da leitura, da escrita e da análise de textos, bem como em torno da discussão sobre os usos da língua portuguesa falada e escrita pelos brasileiros, pois o desenvolvimento e o aprimoramento das habilidades comunicativas de escutar, falar, ler e escrever podem contribuir para que os estudantes consigam expressar de forma adequada seus pensamentos, suas ideias, seus sentimentos e também para que tenham êxito na vida acadêmica e profissional. Além disso, Antunes (2007, 2014), Avelar (2017), Ferrarezi Jr (2014a;b), dentre outros estudiosos têm defendido que, assim como aprendemos a falar ouvindo e falando, aprendemos a ler lendo; aprendemos a escrever escrevendo, revisando o que escrevemos, escrevendo outra vez. Portanto, é o trabalho constante com a língua em uso que pode ampliar a competência comunicativa ${ }^{3}$ dos estudantes.

Contudo, ainda é bastante comum a ênfase em nomenclatura gramatical nas aulas de língua portuguesa através, por exemplo, de atividades de classificação das orações e de seus termos. Esse conhecimento, no entanto, parece ser insuficiente, visto que saber classificar uma oração como subordinada adjetiva restritiva ou explicativa dificilmente conseguirá ampliar o repertório linguístico do estudante a ponto de auxiliá-lo a expressar-se melhor oralmente ou por escrito, por isso é preciso que os educadores, os pais e os alunos busquem afastar-se da ideia de que os estudos de língua portuguesa devem ser vistos apenas como erros e acertos de terminologia gramatical. O trabalho com a língua materna, especialmente na educação básica, precisa estar voltado para o desenvolvimento e o aprimoramento das competências comunicativas dos estudantes.

\footnotetext{
${ }^{3}$ Competência comunicativa: "Conceito desenvolvido pelo sociolinguista norte-americano Dell Hymes, em 1966, que permite ao falante saber o que falar e como falar com qualquer pessoa em qualquer circunstância" (cf. Bortoni-Ricardo, 2004, p. 73).
} 
PERcursos Linguísticos • Vitória (ES) •v. $11 ・ n .28 ・ 2021 ・$ ISSN: 2236-2592

Cabe ressaltar que, embora a memorização da nomenclatura gramatical não seja suficiente para ampliar o conhecimento linguístico dos estudantes, o estudo da gramática da língua não pode ser excluído das aulas de língua portuguesa, conforme Coppi

\footnotetext{
Os linguistas não defendem que o ensino gramatical normativo seja excluído de nossas escolas, mas sim, que ele aconteça de forma diferenciada, contextualizada, ou seja, os alunos devem aprender qual o sentido de uma determinada regra, como ela se dá em uma situação real de uso da linguagem oral e/ou da escrita, já que o ensino tradicional, muitas vezes, não cumpre com o objetivo que lhe é atribuído de preparar o aluno para ler e produzir, de maneira coerente, textos orais e escritos diversos. (COPPI, 2014, p.13)
}

Não há língua sem gramática, tampouco gramática sem língua. Em outras palavras, as pessoas falam uma língua porque conhecem a sua gramática, ainda que não tenham consciência desse saber. Nesse caso, é impossível aprender uma língua para depois aprender a sua gramática, e o conhecimento de língua das crianças que ainda não frequentaram a escola é uma evidência desse fato. A criança se comunica antes de ir à escola porque internalizou naturalmente, desde tenra idade, um conjunto de saberes a partir do contato permanente com a língua utilizada pela comunidade em que está inserida.

No presente artigo, apresentaremos, na primeira seção, a nossa compreensão sobre o ensino de língua materna, tomando por base estudos realizados por importantes linguistas brasileiros. Na segunda seção, mostraremos uma proposta de atividades que foi aplicada a alunos do terceiro ano do ensino médio de uma escola pública da rede estadual do município de Cerrito/RS, no ano de 2019. A atividade baseia-se na crônica do Luís Fernando Veríssimo intitulada "Exigências da Vida Moderna" (VERÍSSIMO, 2017) e foi proposta para a modalidade presencial antes da pandemia. $\mathrm{Na}$ terceira seção, aparecem nossas conclusões e, ao final do texto, as referências bibliográficas.

\section{O Ensino de Língua Portuguesa}

Para ser colocada em uso, a linguagem humana envolve um conhecimento implícito que todo indivíduo traz consigo a respeito de formas e funções dos itens, bem como das construções de sua língua, um conhecimento que os linguistas procuram explicitar.

Segundo Juanito Avelar, 
PERcursos Linguísticos • Vitória (ES) •v. $11 ・ n . ~ 28 ・ 2021 ・ I S S N: ~ 2236-2592$

\begin{abstract}
Não se trata de um saber apreendido de forma passiva, a partir de um conhecimento que vem pronto ou previamente formulado nos compêndios de gramática normativa e nos livros didáticos a que os estudantes têm acesso. O saber gramatical a que me refiro é aquele construído pelo conhecimento natural, espontâneo, intuitivo, que todo falante adquire a respeito de sua língua. (AVELAR, 2017, p.10).
\end{abstract}

A presença desse conhecimento implícito de gramática pode ser percebida, por exemplo, no manejo feito pelos brasileiros dos artigos definidos nos sintagmas nominais. Em certos contextos, o falante pode empregar ou não esses elementos - "Fruta faz bem à saúde", "A fruta faz bem à saúde"; porém, caso decida empregá-los, há, em português, uma posição obrigatória para os artigos: eles devem anteceder o substantivo, como em "o menino", “a menina". Não é possível, em português, construções como "*menino o"4, “*menina a". O falante adquire esse conhecimento sem o ensino formal ofertado nas escolas. As crianças aprendem a ordenação dos elementos nos sintagmas nominais ouvindo e falando o português. Aprendem, portanto, que há, na gramática da língua, aspectos obrigatórios e outros sobre os quais parece existir uma relativa liberdade de escolha. $\mathrm{Na}$ verdade, quando chegam à escola, as crianças já sabem a gramática da língua, no que diz respeito a seus usos reais.

Isso não significa, entretanto, que as gramáticas normativas e os livros didáticos devam ser abandonados ou colocados em segundo plano, mas sim que a abordagem gramatical pode ser enriquecida se os estudantes forem orientados a refletir sobre o conhecimento linguístico que internalizaram naturalmente no processo de aquisição da língua. Não se trata, portanto, de rejeitar as noções normativas no trabalho com a língua em sala de aula, mas de colocar tais noções no conjunto de estudos sobre a linguagem humana.

No entanto, parece ainda haver na própria escola a ideia de que os alunos desconhecem a língua e de que o português é muito difícil. O papel da escola deveria consistir em fortalecer e ampliar o conhecimento intuitivo que o estudante adquiriu por estar em contato com a língua. Nesse sentido, seria importante que, nas atividades de produção, leitura e análise de textos, o estudo da gramática fosse visto como um laboratório de observação e de experimentos linguísticos, em que os alunos pudessem assumir parte da responsabilidade pela construção da aprendizagem.

Segundo Sírio Possenti,

\footnotetext{
${ }^{4} \mathrm{O}$ asterisco é empregado para indicar a agramaticalidade do sintagma.
} 
[...] fazer com que o ensino de português deixe de ser visto como a transmissão de conteúdos prontos e passe a ser uma tarefa de construção de conhecimentos por parte dos alunos, uma tarefa em que o professor deixa de ser a única fonte autorizada de informações, motivações e sanções. O ensino deveria subordinar-se à aprendizagem. (POSSENTI, 1996, p. 96).

O professor poderia estimular o estudante a fazer uma análise comparativa entre diferentes usos da língua portuguesa no Brasil a fim de contrastar as regras que regulam o funcionamento desses usos e compreender as motivações para o surgimento de formas distintas de expressão. Porém, em geral, não há tempo para esse tipo de trabalho que aprimora os saberes de linguagem que os estudantes adquiriram naturalmente porque as turmas escolares precisam "vencer” o conteúdo programático. Os professores se veem, muitas vezes, obrigados a ministrar uma lista quase interminável de conteúdos, o que engessa as possibilidades de trabalho com a língua e, além disso, reduz a autonomia do docente na abordagem gramatical. Para Celso Ferrarezi Jr (2014a, p. 33), "trata-se de currículos descabidamente extensos, currículos que beiram o ridículo na quantidade exorbitante de informação prevista para cada série".

Os programas escolares poderiam ser preparados a partir da compreensão de que os fatos linguísticos estão à disposição em todos os lugares para que os estudantes levantem hipóteses sobre o funcionamento das variedades da língua utilizadas no dia a dia e verifiquem tais hipóteses, bem como para que façam generalizações sobre o comportamento da língua, prevendo também atividades de compreensão e análise de textos orais e escritos, de convívio com os textos literários, de reflexão sobre as relações entre as variedades linguísticas e a situação social e política do país, de produção de textos orais e escritos.

A escola precisa também deixar claro para os alunos que há usos da língua, como a norma-padrão, que ganharam mais aceitação por razões sociais, como o poder econômico e político das pessoas que os adotam. Do ponto de vista linguístico, no entanto, não há usos melhores nem mais certos do que outros. A norma-padrão é uma idealização em torno daquilo que se acredita que a língua deva ser. Assim, o papel da norma-padrão de elemento norteador da disciplina de língua portuguesa poderia ser assumido pela língua real que reflete o conhecimento internalizado pelos falantes, e o estudante poderia tomar consciência 
das diferenças e das semelhanças entre os saberes gramaticais e perceberia a necessidade de respeito à diversidade linguística.

Segundo Carlos Alberto Faraco,

Por isso, nos digladiamos há mais de um século a propósito das mesmas picuinhas gramaticais (e de outras tantas que, de tempos em tempos, os cultores da norma curta inventam). Faz mais de um século que perdemos nosso tempo e nossas energias com questões equivocadas e altamente irrelevantes em matéria de língua. Ainda circular com certa força entre nós um discurso excessivamente purista (ou pseudopurista) sobre as questões linguísticas, como se fôssemos uma sociedade colonial agrária com uma minúscula "república das letras", uma minoria inexpressiva para quem fazia sentido o jogo de salão de apontar "erros de português" em seus pares (FARACO, 2008, p.63, grifo do autor)

A preocupação em aprender as regras que determinam o funcionamento da normapadrão acabou por conceder à disciplina de gramática grande importância nas atividades escolares, o que resultou na crença de que estudar a língua portuguesa é estudar a gramática - "livro que reúne os preceitos do bem falar e do bem escrever". Essa visão, que reduz o saber linguístico a um conjunto de regras, uma lista de classes e de funções gramaticais, tem levado a escola a centrar o estudo da língua na memorização de definições, classificações, que apresentam muitas fragilidades e contribuem pouco para o desenvolvimento da competência comunicativa dos estudantes, pois não ampliam o conhecimento dos alunos sobre o funcionamento da língua nem sobre seus usos. Por exemplo, ao invés de simplesmente classificar orações, seria mais interessante analisar, em textos orais e escritos, como o uso das conjunções ou das locuções conjuntivas estabelece relações de causa-consequência (condicionais, causais, consecutivas), de oposição (adversativas e concessivas), de adição, de conclusão, entre outras. Além disso, aprender a maneira como essas relações contribuem para manter o texto coeso enriquece o repertório linguístico dos alunos.

Os estudantes deixam de estudar as regras que determinam o funcionamento da língua nos textos orais e escritos e passam a memorizar definições e classificações para apresentá-las em uma prova. Memorizar definições e nomenclaturas não é estudar a gramática da língua. Estudar a gramática é verificar como a língua funciona de fato. Observar, por exemplo, ainda com relação aos artigos definidos, conforme Gomes e Mendes (2018, p. 60-61), que a ausência desses elementos pode levar o sintagma a expressar um sentido genérico no português brasileiro, caso desempenhe a função de 
sujeito da oração, como "Fruta faz bem à saúde". Já a frase *“Fruta apodreceu" é agramatical, pois o sintagma nominal sem o artigo não pode ser usado em sentenças episódicas, que expressam um determinado fato ocorrido. A análise do funcionamento desses aspectos gramaticais da língua amplia a consciência dos estudantes sobre os recursos que estão disponíveis para a expressão oral e escrita.

Portanto, os membros de uma comunidade linguística compartilham saberes que incluem regras fonológicas, morfológicas, sintáticas, lexicais, semântico-discursivas, as quais determinam o funcionamento da língua. Esse conhecimento pode ser utilizado pelo professor como ponto de partida para as atividades sobre a língua portuguesa. O professor pode explorar o conhecimento do aluno acerca da variedade linguística de sua comunidade, ajudando-o a desenvolver competências e habilidades necessárias em diferentes contextos comunicativos, inclusive os mais formais. Assim, o professor deixa de ser um mero expositor de regras sobre como a língua deve ser usada e se transforma em um estudioso que auxilia o aluno a entender as regras que ele internalizou de maneira natural antes de chegar à escola.

O reconhecimento da nomenclatura gramatical é essencial para os estudiosos da linguagem - linguistas, professores, gramáticos - pois eles precisam dar nomes às unidades de estudo em uma atividade de análise da língua, importante para a construção do saber sobre a própria língua, inclusive para verificar a consistência de certos termos. Os estudantes, de forma geral, precisam saber usar a língua adequadamente nas diferentes situações comunicativas.

É importante lembrar também que as gramáticas normativas apresentam várias incoerências. Conforme Vavlis e Bastos (2020), os principais problemas da gramática normativa se referem às definições inadequadas, especialmente quanto às classes gramaticais e aos usos de cada uma delas. Dessa forma, a gramática não pode ser venerada como se nela estivessem contidas verdades absolutas sobre a língua. Com relativa frequência, ela descreve usos de língua que não se apoiam nos usos reais das pessoas mesmo em contextos de monitoramento da língua. Como descreve uma língua idealizada, a tradição gramatical insiste, por exemplo, em certas regências verbais que não encontram respaldo na linguagem usada por cientistas, jornalistas, cronistas. É o que acontece, por exemplo, com o verbo “obedecer”, o qual continua a ser classificado, em muitas gramáticas 
tradicionais, como transitivo indireto, ainda que os falantes ignorem a preposição mesmo em situações formais de uso da língua. Nessas situações, são mais comuns estruturas como "Os filhos obedecem os pais" do que "Os filhos obedecem aos pais".

Além disso, não apenas a norma normativa descrita pelas gramáticas tradicionais observa regras que determinam o seu funcionamento. Na verdade, todos os usos da língua são regidos por regras, caso contrário a comunicação seria impossível. Os falantes não podem alterar livremente os princípios que determinam o funcionamento da língua, sob pena de não serem compreendidos. É o que acontece, por exemplo, com a marcação de plural nos sintagmas nominais do português brasileiro coloquial em que o número pode ser marcado apenas no primeiro item do sintagma. No dialeto gaúcho, por exemplo, são comuns formas como "Os guri”, “As guria”, nos quais não há a concordância nominal entre o artigo e o substantivo preconizada pelas gramáticas normativas. Embora desrespeite os preceitos da tradição gramatical, não existe nesses sintagmas uma marcação aleatória do número, visto que são agramaticais, nesse mesmo dialeto, formas como “*O guris”, “*A gurias". Os sintagmas em análise observam regras sofisticadas para marcação do plural, ainda que diferentes daquelas prescritas pela tradição gramatical. Com o passar do tempo, as regras podem assumir variações a fim de se ajustar às necessidades comunicativas dos falantes. Esse fenômeno parece reforçar a ideia discutida acima de que há, nas línguas, uma parte mais flexível e outra mais rígida. Por exemplo, nos sintagmas nominais do português brasileiro coloquial, o artigo não precisa concordar obrigatoriamente em número com o substantivo, mas em gênero sim, como em “O guri”, mas não “*A guri”.

O estudante precisa dominar o maior número possível de usos da língua, inclusive aqueles exigidos em situações ligadas à escrita e à fala formais. O convívio com textos literários, científicos, jornalísticos permite ao estudante internalizar o falar e o escrever de prestígio social. Portanto, não basta ao estudante ter contato com as prescrições gramaticais, ele precisa ter acesso aos fatos reais da língua, aos usos das pessoas que lidam com a língua em situações formais.

Segundo Antunes,

[...] o discurso da escola sobre a língua considera-a como um grande bloco homogêneo; uma entidade uniforme, sem possibilidade de variação. Pelo contrário, nesse discurso, deveria existir uma língua que é falada, e outra que é escrita; uma língua informal, usada nas situações de descontração, e uma língua formal, com um vocabulário e uma sintaxe 
específicos, uma língua para informar, outra para convencer, para seduzir, uma para explicar, outra para refutar etc. Sem o equívoco, como ainda acontece, de acreditar que aquilo que é da língua falada não merece ser explorado. (ANTUNES, 2007, p. 75)

O caráter prescritivo do trabalho com a língua portuguesa na escola é tão forte que mesmo quando elementos da língua falada são mencionados nas atividades servem para reforçar que tais formas são inadequadas. Por exemplo, ao tratar da concordância número/pessoa no paradigma verbal do português brasileiro, o professor apresenta o quadro abaixo e depois explica que é possível usar as duas formas na linguagem coloquial, porém, na linguagem formal ou mais polida, a segunda forma deve ser evitada. Segundo Ferrarezi Jr (2014b), o professor reforça, assim, a ideia de que uma das maneiras de expressão é melhor do que a outra. O mesmo ocorre com os exercícios em que a segunda forma deve ser reescrita para se ajustar à primeira forma.

Quadro 1 - Pronomes pessoais.

\begin{tabular}{|l|l|}
\hline Tradição Gramatical & Português falado em certas regiões do país \\
\hline Eu amo & Eu amo \\
\hline Tu amas & Tu/você ama \\
\hline Ele ama & Ele ama \\
\hline Nós amamos & A gente ama \\
\hline Vós amais & Vocês amam \\
\hline Eles amam & Eles amam \\
\hline
\end{tabular}

Fonte: Autores (2021)

Uma abordagem que se limite a dizer o que deve ser evitado em determinadas situações comunicativas não desenvolve de forma apropriada os contrastes entre os dois paradigmas verbais. Os alunos deveriam refletir sobre as duas formas com base no conhecimento natural que possuem do português. Com relação, por exemplo, ao contraste entre "nós" e "a gente", seria interessante verificar com os alunos em que contextos "a gente" apresenta uma conotação de coletividade que não é expressa por "nós", pronome ligado, em geral, aos enunciadores do discurso. Em "Nós exigimos respeito", o conteúdo 
pode referir-se aos enunciadores da sentença; já em "A gente exige respeito", o conteúdo da sentença pode ter um alcance maior e incluir a coletividade. Esse saber deve ser construído com os estudantes, ao invés de simplesmente dizer que uma forma não é adequada para a linguagem formal.

Além da variação entre a expressão da primeira pessoa do plural - "nós" e "a gente", o professor pode chamar a atenção para a flexão da segunda pessoa do singular que é igual à flexão da terceira pessoa - "Você/tu preparou o bolo", "Ele preparou o bolo", o que resulta em uma simplificação do paradigma verbal, característica encontrada em outras línguas, como o inglês. Com esse trabalho, o professor não vai negar ao aluno o conhecimento do paradigma verbal apresentado nas gramáticas normativas, ele vai, na verdade, propor uma atividade reflexiva sobre os diferentes usos do português brasileiro.

Essa criança precisa entender que a escola lhe oferece um acréscimo produtivo de saberes ao propor um trabalho sobre sua forma de falar, e não uma substituição. A escola, aliás, também tem que entender isso! O trabalho sobre a forma do falar precisa ser mais complexo do que uma mera substituição: precisa ser uma reconstrução. (FERRAREZI JR, 2014a, p. 72).

Seria interessante, portanto, que a escola deixasse de privilegiar o caráter normativo da abordagem gramatical, preocupado com a atribuição de julgamentos de valor sobre as estruturas da língua, avaliando-as em corretas ou incorretas, adequadas ou inadequadas e passasse a dar espaço também para o caráter descritivo-analítico que permite sistematizar os fatos reais da língua e procura explicações científicas para eles. Ao rotular como incorretas formas verbais como "tu ama" em comparação com "tu amas", a escola adota a abordagem gramatical normativa, pois estabelece um juízo de valor; por outro lado, ao procurar contrastar os dois paradigmas verbais com base na reflexão sobre a origem e as consequências de usos das duas formas, a escola assume uma abordagem descritivoanalítica dos estudos gramaticais. As discussões sobre a gramática de uma língua não podem restringir-se à exposição de preceitos sobre o que é certo ou errado, tampouco ao ensino de nomenclaturas separado de atividades práticas que ajudem os estudantes a refletir sobre os recursos disponíveis na língua. O estudante precisa descobrir como o seu conhecimento natural de gramática se organiza para que consiga empregar de maneira consciente e criativa os recursos oferecidos pela língua portuguesa. 
Segundo Avelar,

A rigor, qualquer enunciado da língua se presta a uma análise gramatical, mas nem todo enunciado se apresenta, para fins didáticos, como um dado adequado às reflexões sobre o papel de determinada propriedade na construção de um texto. Um bom conjunto de dados a ser utilizado em sala de aula não deve se limitar a mostrar, por exemplo, que artigos definidos ou indefinidos devem ser usados antes de substantivos como adjuntos adnominais, mas que o emprego dos artigos produz algo interessante sobre o modo como interpretamos aquilo a que o substantivo se refere. (AVELAR, 2017, p. 32).

O trabalho com a língua portuguesa deveria ajudar o aluno a reconhecer de que maneira as estruturas gramaticais contribuem para a construção do sentido, bem como a tornar-se capaz de usá-las conscientemente, estimulando reflexões sobre os fatos presentes na gramática natural dos alunos a partir das intuições dos próprios alunos sobre a língua, para depois apresentá-los, caso necessário, às regras prescritivas da tradição gramatical.

Essa mudança de perspectiva depende também do reconhecimento das inconsistências da tradição gramatical e da adoção de uma postura crítica frente à análise gramatical. Dizer, por exemplo, que "sujeito" é um dos termos essenciais da oração e assumir simultaneamente que há orações sem sujeito não parece consistente. Além disso, é importante reconhecer que a nomenclatura gramatical não deve ser memorizada, mas sim empregada nas reflexões e práticas produtivas sobre a linguagem. É difícil identificar o benefício que há, para o aluno, em identificar os termos da oração se ele não consegue empregar em sua produção textual os recursos gramaticais que a língua coloca à disposição.

O fato é que nossas aulas de língua materna não são feitas para o aluno pensar. Partindo-se quase sempre da pressuposição de que aquilo que o aluno conhece não é a "língua portuguesa" que ele deve conhecer, nossas aulas se fundamentam muito mais na memorização do que seria a tal "língua portuguesa correta" - porém, sem treinamento de aplicação - do que na análise e na compreensão do que se passa realmente nesse universo da língua. Por isso se memoriza tanto (embora apenas para os fins efêmeros da prova) e se raciocina tão pouco. (FERRAREZI Jr., 2014a, p. 40).

A língua de prestígio não se aprende pela repetição de regras, mas sim pelo contato intenso e pela prática com textos orais e escritos nessa língua. Sem o aprendizado satisfatório da linguagem, o estudante terá dificuldades para acessar os demais conhecimentos em sua vida escolar, por isso o estudante tem de saber ler adequadamente e se comunicar, falando ou escrevendo. 
Outro aspecto a ser considerado é que, para ter êxito na comunicação, não é suficiente saber as regras gramaticais referentes às classes de palavras, suas flexões, suas combinações possíveis, a ordem que ocupam nas frases, a concordância. Ainda que sejam importantes, esses conhecimentos não bastam, pois, além do conhecimento linguístico, precisamos de conhecimento de mundo para interpretar os textos orais e escritos. As nossas experiências nos ensinam como o mundo se organiza; por isso é importante promover, na escola, leituras, debates, discussões sobre temas diferentes para que os alunos tenham o que dizer e sejam capazes de compreender o que os outros dizem e escrevem.

Para realizar as atividades de linguagem adequadamente, é interessante explorar também os conhecimentos adquiridos em outras disciplinas, inclusive porque a aprendizagem de qualquer conhecimento depende da linguagem. Em outras palavras, tudo o que aprendemos é acessado pela linguagem. Em geral, os textos produzidos pelos estudantes apresentam mais dificuldades com relação à "profundidade das informações" do que aos problemas gramaticais. Escrever tende a ser difícil porque os estudantes não têm o que dizer. Eles precisam ser estimulados a recorrer a informações, dados, perspectivas, temas acessados nas disciplinas de ciências, história, geografia, matemática a fim de enriquecer suas produções. Na verdade, a escola deveria ofertar aos estudantes oportunidades para ler, escrever, ouvir e falar textos de diferentes gêneros, sobre temas diversos, com o adequado nível de formalidade. Segundo Antunes,

De fato, se queremos promover a inclusão social de nossos alunos, nada mais urgente do que incluí-los no mundo da leitura, da escrita, da análise, da reflexão crítica e criadora; da posse da palavra, enfim! (ANTUNES, 2007, p. 152).

\section{Proposta de atividades}

Nesta seção, apresentaremos uma sugestão de atividades que foram aplicadas a alunos do terceiro ano do ensino médio de uma escola estadual, localizada no município de Cerrito/RS. A proposta baseia-se na crônica do Luís Fernando Veríssimo intitulada "Exigências da Vida Moderna" e foi proposta para a modalidade presencial, antes da pandemia, objetivando conduzir os alunos a refletirem efetivamente sobre os elementos presentes no texto. Essa atividade se distingue das atividades comuns em livros didáticos, por exemplo, porque busca fazer com que os alunos interpretem o texto e reflitam detalhadamente sobre os elementos utilizados na construção do sentido do texto. 
Leia o texto.

\section{EXIGÊNCIAS DA VIDA MODERNA}

por causa do ferro.

Dizem que todos os dias você deve comer uma maçã

E uma banana pelo potássio.

E também uma laranja pela vitamina C. Uma xícara de chá verde sem açúcar para prevenir a diabetes.

Todos os dias deve-se tomar ao menos dois litros de água. E uriná-los, o que consome o dobro do tempo.

Todos os dias deve-se tomar um Yakult pelos lactobacilos (que ninguém sabe bem o que é, mas que aos bilhões, ajudam a digestão). Cada dia uma Aspirina, previne infarto. Uma taça de vinho tinto também. Uma de vinho branco estabiliza o sistema nervoso. Um copo de cerveja, para... não lembro bem para o que, mas faz bem. O benefício adicional é que se você tomar tudo isso ao mesmo tempo e tiver um derrame, nem vai perceber.

Todos os dias deve-se comer fibra. Muita, muitíssima fibra. Fibra suficiente para fazer um pulôver.

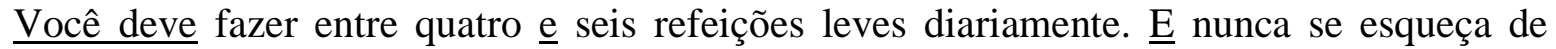
mastigar pelo menos cem vezes cada garfada. Só para comer, serão cerca de cinco horas do dia...

E não esqueça de escovar os dentes depois de comer. Ou seja, você tem que escovar os dentes depois da maçã, da banana, da laranja, das seis refeições e enquanto tiver dentes, passar fio dental, massagear a gengiva, escovar a língua e bochechar com Plax. Melhor, inclusive, ampliar o banheiro e aproveitar para colocar um equipamento de som, porque entre a água, a fibra e os dentes, você vai passar ali várias horas por dia.

Há que se dormir oito horas por noite e trabalhar outras oito por dia, mais as cinco comendo são vinte e uma.

Sobram três, desde que você não pegue trânsito. As estatísticas comprovam que assistimos três horas de TV por dia. Menos você, porque todos os dias você vai caminhar ao menos meia hora (por experiência própria, após quinze minutos dê meia volta e comece a voltar, ou a meia hora vira uma).

E você deve cuidar das amizades, porque são como uma planta: devem ser regadas diariamente, o que me faz pensar em quem vai cuidar delas quando eu estiver viajando.

Deve-se estar bem informado também, lendo dois ou três jornais por dia para comparar as informações. 
PERcursos Linguísticos • Vitória (ES) •v. $11 ・ n . ~ 28 ・ 2021 ・ I S S N: ~ 2236-2592$

Ah! E o sexo! Todos os dias, tomando o cuidado de não se cair na rotina. Há que ser

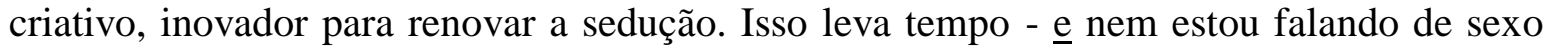
tântrico.

Também precisa sobrar tempo para varrer, passar, lavar roupa, pratos e espero que você não tenha um bichinho de estimação. Na minha conta são 29 horas por dia.

A única solução que me ocorre é fazer várias dessas coisas ao mesmo tempo! Por exemplo, tomar banho frio com a boca aberta, assim você toma água e escova os dentes. Chame os amigos junto com os seus pais. Beba o vinho, coma a maçã e a banana junto com a sua mulher... na sua cama.

Ainda bem que somos crescidinhos, senão ainda teria um Danoninho e se sobrarem 5 minutos, uma colherada de leite de magnésio.

Agora tenho que ir.

É o meio do dia, e depois da cerveja, do vinho e da maçã, tenho que ir ao banheiro.

E já que vou, levo um jornal... Tchau!

Viva a vida com bom humor!!!

Disponível em:<https://www.pensador.com/exigencias_da_vida_moderna/2/

ROTEIRO DE LEITURA - Crônica Exigências da vida moderna

ROTEIRO ORAL

Vocabulário:

Potássio - Diabetes - Yacult - Aspirina - Derrame - Pulôver - Plax - Danoninho

Fase de pré-leitura:

1) Como é a alimentação de vocês? Vocês conseguem manter uma alimentação saudável?

Se não, por quê?

2) Vocês fazem alguma coisa para prevenir a diabetes, a pressão alta e o infarto? Quais?

3) Vocês conseguem fazer todas as refeições com calma, mastigando corretamente?

4) Têm alimentações leves e variadas durante o dia?

5) Cuidam corretamente dos dentes?

6) Dormem oito horas por dia? Mais ou menos?

7) Praticam atividades físicas? Se não, por quê?

8) Conseguem manter as amizades e sair, se divertir, frequentemente?

9) Conseguem manter-se bem informados sempre? 
10) Quais são as principais exigências da vida moderna?

11) Há vantagens em fazer várias coisas ao mesmo tempo?

12) Vocês conseguem organizar o tempo de maneira adequada?

Leitura do texto.

Fase de leitura:

1) Quais expectativas você criou em relação ao texto ao ler o título "Exigências da vida moderna"?

2) Que tipo de texto é esse? Onde circula este tipo de textos?

3) Qual o público-alvo?

4) Qual assunto do texto?

5) O tamanho da crônica tem a ver com o assunto do qual ela trata? Por quê?

6) Em muitos momentos, no texto, o autor utiliza verbos no imperativo, como em: "você deve", "deve-se", "beba", "coma" (sublinhadas no texto). O uso do imperativo tem qual objetivo?

7) Qual a intenção do autor ao repetir várias vezes a expressão "não esqueça"?

8) Qual sentido a repetição do "e" (sublinhada no texto) produz?

9) Qual efeito de sentido é produzido com o trecho "não lembro bem para o que, mas faz bem"? (linhas 8 e 9)

10) Na linha 10 diz: "se tiver um derrame, nem vai perceber". Qual é o sentido produzido com isso?

11) Na linha 11, qual a intenção do autor ao utilizar o grau superlativo em "muitíssima"?

12) E qual o sentido obtido com a frase: "fibra suficiente para fazer um pulôver" (linha 11)?

13) Quando o autor sugere colocar um aparelho de som no banheiro (linha 17), qual o seu propósito?

14) Na linha 22, a expressão "menos você" causa um impacto em vocês? Por quê?

15) Na linha 21, a expressão "desde que" pode ser substituída por qual outra sem perder o sentido original?

16) Ao comparar as amizades a uma planta, na linha 24 , o autor tem a intenção de quê?

17) Qual objetivo do autor ao dizer, na linha 28, que não se pode cair na rotina?

18) Na linha 30, "espero que não tenha um bichinho de estimação" provoca que tipo de reflexão? 
PERcursos Linguísticos • Vitória (ES) •v. $11 ・$ •n. 28 • 2021 • ISSN: 2236-2592

19) Como solução para o ser humano conseguir realizar tantas exigências, qual o conselho irônico do autor?

20) Qual a intenção do autor ao aconselhar que sejam feitas várias coisas ao mesmo tempo (linha 32)?

21) Ao dizer "viva a vida com bom humor" no final do texto, o escritor transmite qual ideia?

\section{ROTEIRO ESCRITO}

1) Qual a ideia principal transmitida no texto? Explique como ela foi construída.

2) O tamanho do texto está relacionado ao assunto do qual ele trata? Justifique.

3) Como o autor da crônica trata a questão das exigências da vida moderna? Qual objetivo dele?

4) Justifique porque você concorda ou discorda do autor em relação ao assunto tratado no texto.

\section{Análise da proposta de atividades}

Inicialmente é apresentado um vocabulário, acreditamos que esse item é importante para que sejam comentados os significados das palavras "estranhas" aos alunos. Muitas vezes, os alunos mais tímidos não questionam quando têm dúvidas e não possuem internet ou acesso a materiais para pesquisarem, então é importante que o professor converse com os estudantes sobre o significado dessas palavras.

$\mathrm{Na}$ fase de pré-leitura, espera-se conduzir os alunos à percepção de como as exigências da vida moderna se relacionam a seus cotidianos, proporcionando um elo com a narrativa pilhérica da crônica. A fase de pré-leitura, conforme Ferreira e Sardinha (2015), é de extrema importância para despertar o interesse pela leitura nos alunos, em especial dos anos iniciais do ensino básico.

Posteriormente, na fase de leitura do texto, são explorados os recursos linguísticos utilizados na construção de sentido do texto. Já na leitura do título, espera-se que o aluno formule hipóteses verossímeis quanto ao conteúdo da crônica, demonstrando, assim, capacidade de interpretação e abstração do texto.

Em relação ao gênero, o texto trata-se de uma crônica, em vista da narrativa de situações cotidianas sob uma perspectiva individual, frisando aspectos como humor, crítica 
PERcursos Linguísticos • Vitória (ES) •v. $11 ・$ •n. 28 • 2021 • ISSN: 2236-2592

e ação, tendo presentes em sua tessitura personagem, tempo e espaço; gênero literário comumente veiculado em jornais, em magazines, em blogs e sites. Nesse cenário, considerando-se os veículos de publicação de uma crônica, poder-se-ia dizer de modo geral que o público-alvo é idêntico àquele que consome esses materiais, contudo, pelo perfil subentende-se que sejam adultos, homens ou mulheres, que não apenas vivem essas “exigências da vida moderna" como também devem comungar das mesmas críticas.

Assim, espera-se que os alunos percebam que o assunto do texto abarca as pretensas exigências de uma vida saudável, impostas pelas modernas concepções de saúde e bemestar, as quais, criticadas pelo autor através da bem humorada narrativa individual, em que o autor cria situações impossíveis a partir dessas demandas. Além disso, o tamanho da narrativa e o fluxo do texto restringem-se ao período de prazos exíguos narrados pelo autor, tal que se inicia e termina no mesmo ímpeto da falta de tempo e, nesse ínterim, busca-se apresentar considerável volume de informações.

A utilização dos verbos no imperativo, por definição gramatical, exara uma ordem, um desejo ou um pedido; nesse particular, o imperativo chama atenção do leitor por meio de ordens daquilo que seriam as exigências necessárias para uma vida saudável. Espera-se que os alunos percebam que a utilização do imperativo se trata de um recurso estilístico voltado à ênfase que o autor deseja dar aos elementos do texto. Já o conectivo "e" tem sentido aditivo, portanto, o autor busca, pela sua repetição, avultar o quantitativo de ações necessárias a uma vida saudável, produzindo no leitor o sentimento de excesso.

No trecho "não lembro bem para o que, mas faz bem", espera-se que os alunos compreendam que é um recurso de humor e de crítica. O autor não lembra para que serve, mas sabe que tem de fazer, o que deixa implícito a crítica de que não há sobre as exigências da vida moderna uma leitura mais profunda, sendo elas aceitas sem maiores questionamentos e cumpridas como um dogma. O fluxo do texto produz humor justamente porque subjaz a crítica ao lado do enunciado de tais exigências.

Adiante, temos, por exemplo: uso de adjetivo no grau superlativo, como um recurso para enfatizar o exagero, o grau extremo; uso de figuras de linguagem como uma hipérbole, como forma de enfatizar a sua crítica e uma ironia para enfatizar o excesso de tempo que demanda passar no banheiro em detrimento de outras atividades, como trabalhar, passear; uso de um vocativo em "menos você" no qual espera-se que os alunos percebam que essa 
PERcursos Linguísticos • Vitória (ES) •v. 11 •n. 28 • 2021 • ISSN: 2236-2592

utilização enfatiza a crítica às exigências modernas de uma vida saudável ao salientar que os sectários dessas recomendações precisariam de um dia com mais de 24 horas. Além disso, temos uso de expressões adverbiais, metáforas e outros recursos linguísticos.

Em relação ao roteiro escrito, espera-se que os alunos respondam, de forma escrita, com base no que foi discutido oralmente na fase da leitura. Essa etapa tem por finalidade o desenvolvimento da competência discursiva dos alunos, visto que a maneira de organizar as ideias oralmente é diferente da escrita.

Desse modo, em um primeiro momento, durante a aplicação da proposta, os alunos apresentaram uma certa resistência em relação ao roteiro oral, provavelmente, por não estarem acostumados com atividades desse tipo. Em função disso, foi necessário utilizar estratégias que estimulassem a participação de todos, como, por exemplo, chamar pelo nome, direcionando cada pergunta a um aluno aleatoriamente; usar um vocabulário próximo ao usual dos alunos, buscando diminuir a distância entre professor e alunos. Assim, no decorrer da aula, todos passaram a participar da construção da discussão e contribuíram com seus argumentos nas respostas das questões propostas.

\section{Considerações finais}

Sabemos que o professor de língua materna vive constantemente o dilema sobre como ensinar os conteúdos gramaticais que são impostos nos programas das escolas. Assim, optamos por apresentar, além das concepções teóricas, uma atividade, a título de exemplificação, visto que acreditamos que tal atividade tem por objetivo favorecer o desenvolvimento da competência comunicativa dos alunos. Nosso intuito é reforçar que há como desenvolver os conhecimentos gramaticais dentro do trabalho com a leitura, a escrita e a oralidade/escuta sem que sejam atividades mecânicas, baseadas na fixação de regras e nomenclaturas por si só.

$\mathrm{Na}$ análise da crônica, foram trabalhadas questões relacionadas a modos verbais, figuras de linguagem, conjunções, coerência e coesão, tudo dentro do texto, sem exigir que o aluno decorasse respostas engessadas ou respondesse mecanicamente. Longe disso, atividades assim despertam interesse na turma, já que os alunos têm a oportunidade de discutir as questões de modo que opiniões distintas podem ser refletidas e debatidas a partir do sentido produzido no texto. 
Durante a realização da atividade, os alunos interagiram colaborativamente na construção dos argumentos para responder às perguntas orais, o que agrega muito não só na aprendizagem do conteúdo, mas também no desenvolvimento das competências relacionadas ao convívio com os colegas e ao trabalho em equipe. Em virtude disso, consideramos que a atividade proposta contempla o que os teóricos ressaltam a respeito de como devem ser as aulas de língua materna, tendo em vista que foi oportunizado aos alunos um momento de reflexão sobre os elementos utilizados na construção do sentido da crônica.

Desse modo, acreditamos que, no ensino básico, é imprescindível que o professor tenha em mente a necessidade de promover atividades que conduzam o aluno a, sobretudo, refletir sobre os usos linguísticos. Ressaltamos que não basta o aluno decorar uma lista de termos e as respectivas nomenclaturas; ele precisa saber em qual contexto determinado emprego é adequado ou não. Mais do que isso, é fundamental que o professor priorize atividades que promovam o desenvolvimento da capacidade de ler um texto e compreender o sentido do que foi lido; de conseguir se expressar e, ainda, saber como se expressar nas mais diversas situações.

Assim, finalizamos destacando Antunes, a qual afirma que "não promover o desenvolvimento de certas habilidades de uso da linguagem corresponde a uma importante estratégia de manter os privilégios e os poderes nas mãos de poucos" (ANTUNES, 2014, p. 43).

\section{Referências}

ANTUNES, Irandé. Muito além da gramática: por um ensino de línguas sem pedras no caminho. São Paulo: Parábola Editorial, 2007.

ANTUNES, Irandé. Gramática Contextualizada: limpando ‘o pó das ideias simples'. São Paulo: Parábola Editorial, 2014.

AVELAR, Juanito Ornelas de. Saberes gramaticais: formas, normas e sentidos no espaço escolar. São Paulo: Parábola, 2017.

BORTONI-RICARDO, Stella Maris. Educação em língua materna: a sociolinguística em sala de aula. São Paulo: Parábola Editorial, 2004.

COPPI, Danielle dos Santos Mendes. O ensino de língua portuguesa e a questão do preconceito dialetal sob a ótica da sociolinguística. Monografia. Universidade Estadual da Paraíba, Centro de Humanidades, 2014. Disponível em 
<https://dspace.bc.uepb.edu.br/jspui/bitstream/123456789/4367/1/PDF\%20\%20Danielle\%2 0dos\%20Santos\%20Mendes\%20Coppi.pdf>. Acesso em 22 de abril de 2021.

FARACO, Carlos Alberto. Norma Culta Brasileira: desatando alguns nós. São Paulo: Parábola Editorial, 2008.

FERRAREZI Jr., Celso. Pedagogia do silenciamento: a escola brasileira e o ensino de língua materna. São Paulo: Parábola Editorial, 2014a.

FERRAREZI Jr., Celso. O estudo dos verbos na educação básica. São Paulo: Contexto, 2014b.

FERREIRA, Sílvia de Oliveira; SARDINHA, Maria da Graça Guilherme de Almeida. A leitura: a importância $\operatorname{do}(\mathrm{s})$ texto(s). Disponível em: <https://ubibliorum.ubi.pt/handle/10400.6/6152>. Acesso em 23 de abril de 2021.

GOMES, Ana Quadros; MENDES, Luciana Sanchez. Para conhecer semântica. São Paulo: Contexto, 2018.

POSSENTI, Sírio. Por que (não) ensinar gramática na escola. Campinas: Mercado das Letras, 1996.

VAVLIS, Paula Di Sessa; BASTOS, Neusa Maria Oliveira Barbosa. As gramáticas tradicional e gerativa: teorias linguísticas e modelos gramaticais. In: $20^{\circ}$ Congresso Nacional de Iniciação Científica, 2020, São Paulo. Anais do Conic-Semesp/Volume 8 FSA - UNIFENAS - UNIFEOB - UNIPROJEÇÃO, 2020, p. 1 - 6.

VERÍSSIMO, Luiz Fernando. Exigências da vida Moderna. Recanto das Letras. Disponível em: <https://www.recantodasletras.com.br/humor/1008880> Acesso em: fev. de 2017. 